\title{
Experiência turística em museus: percepções de gestores e visitantes
}

Tourist experience in museums: perceptions of managers and visitors

\section{Marlusa de Sevilha Gosling}

Federal University of Minas Gerais (UFMG), Faculty of Economics, Department of Management Sciences, Av. Pres. Antônio Carlos, 6627 - Pampulha, Belo Horizonte - MG, 31270-901, Brasil, marlusa@ufmg.br

João Albino Silva

University of Algarve (UAlg), Faculty of Economics, Campus de Gambelas 8005 - 139 Faro, jsilva@ualg.pt

Júlio Mendes

University of Algarve (UAlg), Faculty of Economics, Campus de Gambelas 8005 - 139 Faro, jmendes@ualg.pt

\section{Mariana de Freitas Coelho}

Federal Center for Technological Education (CEFET-MG), Department of Management Sciences, MG, 35503-822, Brasil, marifcoelho@gmail.com

\section{Italo Brener}

Federal Center for Technological Education (CEFET-MG), Department of Management Sciences, MG, 35503-822, Brasil, italobrener@hotmail.com

\section{Resumo}

O objetivo do artigo foi compreender as diferenças entre as percepções de gestores de museus e a experiência dos visitantes. A metodologia foi qualitativa e exploratória e abrangeu três perspectivas diferentes: as diretrizes dos gestores de museus; a opinião geral de visitantes (préexperiência) e a experiência de visitantes (pós-visita). Dados foram coletados usando entrevistas semi estruturadas com os três grupos, em Belo Horizonte, Minas Gerais, Brasil. Como resultados, aponta-se que existem incongruências entre as visões de gestores e dos visitantes. Entrevistados destacaram a falta de interesse em visitar museus e que sua visita foi regida pela influência social e pela curiosidade. Gestores destacaram aspectos distintos que afetam a experiência em museus: a interatividade, a independência dos visitantes, os eventos e programação complementar. Os autores agradecem o apoio da Fapemig e da Capes.

Palavras-chave: Museus, marketing de museus, percepções de gestores, percepções de visitante, experiência turística.

\section{Abstract}

The purpose of this paper is to comprehend differences between museum's managers perceptions and visitors' experience. The methodology is qualitative and exploratory comprising three different perspectives: museum's managers' directives, visitors' general opinion (pre experience) and visitors' post experience. Data were collected through interviews with all the three groups at Belo Horizonte, Minas Gerais, Brazil. Results show that there are incongruences between managers and visitors' view. Some interviewees highlighted their lack of interest in visiting museums and others affirmed their visit was conditioned to social influence and curiosity. Managers highlighted distinct aspects of museums' experience: interactivity, visitors' independence and events schedule. The authors acknowledge the financial support given by Fapemig and Capes.

Keywords: Museums, museum marketing, managers' perceptions, visitor's perception, visitor's experience.

\section{Introdução}

A economia da experiência pode ser definida como o processo de vivenciar um acontecimento único e marcante. De acordo com (Pine \& Gilmore, 2011, 1998), as empresas e instituições, apostam em proporcionar experiências memoráveis para seus consumidores, isto é, na economia da experiência se diferenciar apenas por meio de produtos e serviços não é mais suficiente para satisfazer o cliente (Pine \& Gilmore, 2011). Os museus, com sua função social ligada à educação e à cultura, correspondem a instituições capazes de proporcionar experiências para a população (Gosling, Pereira, Vera, Coelho, \& Lima, 2014b), que podem resultar em aprendizado e transformação dos visitantes.

Para entender os museus como provedores de experiências, é necessário compreendê-los também como espaço destinado ao púbico, conforme sugerido por Sheng e Chen (2012). O museu acumula funções como: ponto de visitação com papel social; um espaço de armazenamento de coleções; um espaço para pesquisa e exibição de acervos, e também proporciona educação e recreação a seus visitantes. Tais funções precisam ser geridas pelos gestores de museus, que muitas vezes encontram desafios para realçar as experiências vividas no espaço. Pesquisas como a de Falk e Dierking (1992), Larsen (2007) e Sheng e Chen (2012) têm sido desenvolvidas no intuito de entender melhor a experiência dos visitantes de museus.

Compreender os processos de contextos construídos pelos visitantes permite a visualização das escolhas dos mesmos nesses espaços culturais (Falk \& Dierking, 1992). A co-criação de experiências únicas, exclusivas e personalizadas é proporcionada por um ambiente de experiência advindo de interações de alta qualidade entre os atores, passando assim, a ser fonte para a criação de valor (Prahalad \& Ramaswamy, 2004; Pine \& Gilmore, 1998). Porém, o papel que o visitante irá assumir no museu depende do grau de passividade dos visitantes e da autenticidade promovidos pelo museu (Thyne, Hede \& White, 2009).

A literatura de experiências em museus tem abordado aspectos prévios, durante e após a visita dos indivíduos (Kirchberg \& Tröndle, 2012). Porém, no Brasil, poucos estudos têm enfatizado a experiência do visitante de maneira holística (Gosling et al., 2014b).

Diante do exposto, apesar dos museus serem ambientes bastante propícios para a promoção de experiências, nem sempre os museus são geridos com foco na cultura de experiência, mas apenas como mais um serviço ofertado de uma organização para a comunidade, com ênfase na promoção da aprendizagem. 
Neste contexto, este artigo pretende investigar como estes espaços estão sendo percebidos pelos seus públicos na ótica dos gestores e dos visitantes. O objetivo desta pesquisa foi de forma holística, investigar diferenças entre as percepções da experiência de visitação entre gestores do museu e visitantes.

Os museus de Belo Horizonte, Minas Gerais, Brasil, possuem uma relação de aproximação com seu público, constituindo um campo relevante para esta pesquisa. Este estudo foi embasado em entrevistas com 7 gestores de 6 museus distintos, impressões prévisita de 30 visitantes potenciais e moradores de Belo Horizonte, MG e, por fim, 18 visitantes que descreveram sua experiência de visita em um museu específico. Foi possível construir uma investigação das impressões produzidas pelos visitantes em suas experiências positivas e negativas e ao mesmo tempo, representar uma comparação entre os discursos.

\section{Referencial teórico}

\subsection{As alterações no papel dos museus}

As alterações no modo como os museus se relacionam com os visitantes sofreu alterações significativas ao longo da história. Segundo Doering (1999), em princípio, os museus eram vistos como instituições que tinham como principal objetivo o cuidado com a coleção de artefatos históricos (McLean, 1995) e, nesse sentido, os visitantes eram vistos como intrusos ou estrangeiros. Frases como "não toque" enfatizam a relevância de se conservar as obras de arte (Grenier, 2010). O trabalho dos museus, portanto, era mais introspectivo e baseado em uma visão tradicional onde se devia andar calmamente em um lugar onde havia um trajeto definido (Thyne, 2000).

Posteriormente, os museus passaram a aceitar os visitantes e entenderam que deveriam tratá-los não como intrusos, mas como "convidados". Assim, o foco dos museus mudou em direção ao oferecimento de instrução de qualidade, destacando seus aspectos educacionais (McLean, 1995). As coleções e os conhecimentos armazenados fisicamente nos espaços museais começaram a ser disseminados através do estímulo à visitação e à contemplação daquilo que os museus tinham para oferecer.

Em um estágio mais recente, os museus começaram a enxergar o visitante como cliente e, dessa forma, já não procuram impor aos visitantes as experiências que acharem melhor, mas buscam entender o que os visitantes desejam obter e quais os tipos de experiência devem ser ofertados para se garantir a satisfação do público. É nessa fase que as pesquisas de marketing ganharam novos impulsos para apoiar as decisões de gestores. Deste modo, só recentemente os produtos museais puderam ser legitimamente considerados como experiências do museu (McLean, 1995).

Rentscheller (2002) confirma estes achados ao estudar 171 artigos de marketing de Museus publicados entre 1995 e 2000. O autor sintetiza seus achados em três períodos que contribuem para o entendimento dos avanços dos museus na perspectiva do marketing museal. O primeiro período, de Fundação (1975-1984) enfatizou aspectos educativos do público. O segundo período, da Profissionalização (1985-1994), indicou a necessidade de aplicação de ações de marketing em organizações artísticas. Por fim, o último período, da Descoberta (1995-2002), começou a utilizar técnicas de marketing em locais como museus.

Na última década, os museus começaram a utilizar tecnologias de informação e comunicação, como mídias sociais e smartphones para tentar evitar que a visita se torne entediante principalmente entre os visitantes mais jovens (Del Chiappa, Andreu \& Gallarza, 2014).

Assim, os museus deixaram de atuar passivamente na disseminação de informações e buscaram reformular suas atividades para atrair visitantes e proporcionar experiências mais agradáveis para seu público (Silva \& Santos, 2011). Portanto, entender a experiência do visitante torna-se essencial para acompanhar as mudanças percebidas pelos visitantes de museus (Gosling, Coelho, \& Resende, 2014a) e adequar ações estratégicas por parte dos gestores.

\subsection{As dimensões da experiência}

A economia da experiência é considerada uma nova era da economia proposta na década de 90, em artigo de Pine e Gilmore (1998). A ideia desses autores é que a economia vem evoluindo ao longo do tempo e passou da venda de commodities para a venda de bens, depois para a venda de serviços e exalta a venda de experiência como um processo econômico evolutivo. Para Pine e Gilmore (1998), as empresas não devem se perguntar se entrarão no mercado da experiência, mas quando e como entrarão se quiserem permanecer competitivas nesse novo estágio da economia.

É importante notar que o termo mercado da experiência aponta para o desejo humano de experiências (Hosany \& Witham, 2009). Pine e Gilmore (1998) identificaram quatro dimensões do consumo de experiências e as dividiram em dois níveis: 1) grau de envolvimento (passivo versus ativo) e 2) o desejo com o qual o cliente se conecta ou se envolve com determinado evento (absorção versus imersão). As quatro dimensões da experiência são: 1) entretenimento (absorção passiva), 2) educacional (absorção ativa), 3) escapista (imersão ativa) e 4) estética (imersão passiva). Percebese que todas essas quatro dimensões podem estar presentes em uma experiência turística ou de visita a um museu.

A experiência do consumidor é caracterizada como uma avaliação multidimensional e holística, podendo ser definida em termos de cinco dimensões (relações), segundo Schmitt (2000):

1) experiências sensoriais (sentidos);

2) experiências afetivas e emoções (sentimento);

3) experiências de criatividade cognitivas (pensamento);

4) experiências físicas, comportamentos e estilos de vida (ação) ; 5) experiências de identidade social (relacionar-se).

Assim, após a compreensão do mercado da experiência e as ideias sobre a economia da experiência propostas por Pine e Gilmore (1998), Schmitt (2000) propôs o termo marketing da experiência o que fomentou discussões sobre o tema entre pesquisadores da área de gestão e marketing.

Shaw \& Ivens (2002) afirmam que existe um consenso entre esses pesquisadores de que a experiência inclui vários elementos e 
provê um mix de sensações físicas, emocionais, intelectuais e espirituais.

Goulding (2000) reforça a noção de que a experiência deve ser entendida como um processo mediado por um número de aspectos sócioculturais, cognitivos, psicológicos, condições físicas e ambientais de forma interligada. Por isso, a experiência do visitante se relaciona com percepções pessoais e ambientais dos mesmos, englobando uma série de fatores.

O turista atual não se satisfaz em apenas contemplar atrativos turísticos e conhecimentos superficiais, mas quer também adquirir conhecimentos mais intensos e profundos dos lugares que visitam (Pezzi, 2015).

Experiências são pessoais e variam de acordo com que os indivíduos percebem e reagem a lugares e produtos turísticos específicos (Munar \& Jacobsen, 2014). Cidadãos consumidores de entretenimento tendem a se conectar às experiências mais relevantes e que estejam alinhadas com seu estilo de vida e definem determinadas experiências de consumo como representantes de algo mais do que experiências aparentemente comuns de consumo (Hiller, 2011).

A era da experiência foca no oferecimento de recursos memoráveis, encenados, pessoais e que promovem sensações (Pine \& Gilmore,1998). Dessa forma, os museus estão inseridos nesse contexto como espaços que promovem experiências e podem interagir com seus visitantes. Tanto os indivíduos são influenciados pelos museus quanto os museus ganham novos significados dados pelas pessoas que os visitam. Existe, portanto, um processo de ressignificação.

\subsection{Expectativas quanto à experiência da visitação}

Falk e Dierking (1992) sugerem que a experiência de visitantes de museus não é estática, mas sim um processo dinâmico que envolve o antes, o durante e o depois da visita, que resulta de interações que são influenciadas por diferentes contextos. De forma semelhante, Larsen (2007) diz que a experiência não acontece somente no momento da visitação em si, mas é um fenômeno psicológico acumulado, que influência todos os três estágios. A memória e os sentimentos presentes no antes, no durante e no depois podem afetar as expectativas, em um processo circular e contínuo.

Segundo Soares (2010), a experiência museológica está intrinsecamente presente no indivíduo e é definida por um conjunto de subjetividades que caracteriza essa relação específica do humano com o real. A subjetividade, deve ocupar um lugar proeminente na experiência museal (Soares, 2010). Desta feita, cabe investigar os gatilhos pessoais na visitação e recomendação de museus.

Pensando nesta ideia de avaliar o antes de uma experiência, isto é a expectativa da experiência de visitantes de museus, Sheng e Chen (2011) analisaram o conteúdo de diários escritos por visitantes de um museu. Por meio de análise fatorial exploratória, os autores identificaram cinco tipos de expectativas de experiência:

1) facilidade e diversão;
2) entretenimento cultural;

3) identificação pessoal;

4) rememoração da história;

5) escapismo.

A dimensão relacionada às mais altas expectativas foi facilidade $e$ diversão, corroborando com as ideias de Weil (2000) que ressalta que os museus mais modernos, oferecem além do tradicional acervo histórico, elementos de recreação.

Três necessidades humanas podem ser satisfeitas durante uma visita a um museu de acordo com McLean (1997). A primeira é o encontro com uma atmosfera particular que é diferente da vida comum, que foge à rotina, isso geralmente ocorre em contato com as exposições artísticas. A segunda é possibilidade de vivenciar experiências interativas juntamente com outras pessoas, principalmente com amigos e familiares. A terceira refere-se ao fato de que os museus podem traduzir as informações exibidas em valores pessoais, cumprindo seu papel educacional. Apesar de apenas no segundo item o autor falar de experiência, todas essas necessidades podem ser embrulhadas por perspectivas experienciais de forma a encantar e seduzir os visitantes de um museu, com foco nas dimensões da experiência proposta por Pine e Gilmore (1998).

Os elementos da experiência têm uma conexão direta com as experiências na visitação a museus, assim, os principais elementos aqui discutidos foram: as expectativas e interesse de McLean (1997) - fuga da rotina, sociabilidade e educação; as de expectativas de experiência de Sheng e Chen (2011) - facilidade e diversão, entretenimento cultural, identificação pessoal, rememorar a história e escapismo; as dimensões da experiência (Pine \& Gilmore, 1998 - entretenimento, educacional, escapista e estética) e, finalmente, os módulos estratégicos de experiências (Sentidos, Sentimento, Pensamento, Ação e Relacionar-se).

\section{Metodologia}

Esta pesquisa é um estudo qualitativo, de natureza exploratória, que buscou identificar a percepção de gestores e visitantes de museus de maneira holística. Para tanto, o estudo abordou tanto a perspectiva dos gestores de diversos museus de Belo Horizonte e região, quanto as percepções de moradores locais pré visita e os relatos de visitantes após a experiência em um museu específico.

A pesquisa foi concebida de forma a obedecer aos princípios éticos e às boas práticas comuns às investigações da área, por envolver indivíduos.

Foram aplicados três roteiros distintos para cada grupo, que serviram como instrumento para a coleta de dados. Um direcionado aos gestores dos museus (Grupo G), outro aos moradores locais e, portanto, considerados visitantes potenciais (Grupo A) e outro às pessoas que realizaram visitas aos museus (Grupo B).Os roteiros foram baseados em Gosling et al. (2014b), Gosling et al. (2014a) e Schmitt (2000) e estão disponíveis no Apêndice.

Os dados foram coletados por meio de entrevistas com sete gerentes de seis museus na região de Belo Horizonte, Minas 
Gerais, Brasil. As entrevistas aconteceram presencialmente, no museu em que cada gestor trabalhava.

Moradores da cidade de Belo Horizonte, todos universitários, foram convidados a responder sobre seus hábitos de lazer e percepções sobre visitas a museus. Dos 35 convidados, um grupo de 30 pessoas relatou sua opinião geral sobre os museus com base em um roteiro semiestruturado respondido remotamente via Google Docs em setembro de 2015. Esse grupo foi chamado de grupo de visitantes potenciais porque, efetivamente, qualquer morador da cidade pode considerar a visita a um museu como fonte de experiência e entretenimento, visto que há, na cidade, um circuito cultural de museus em determinada localização central, muito visitada.

Ainda, foram coletados 18 relatos da experiência vivenciada em uma visita a um museu local, o Centro Cultural Banco do Brasil Belo Horizonte (CCBB-BH) no final de 2015. Durante a visita, a exposição em questão e os relatos referem-se a um roteiro estruturado sobre esta experiência.

Note-se que tanto no grupo de visitantes potenciais quanto no grupo de pessoas que realizaram uma visita ao museu específico, a seleção de entrevistados foi feita por conveniência e acessibilidade. Como o estudo foi exploratório e, portanto, não se pretende generalizar resultados, ou mesmo propor um modelo geral de motivações e experiência em museus, considera-se que essa abordagem adequada..

A análise dos dados utilizou a técnica de análise de conteúdo. As respostas obtidas foram analisadas primeiramente por grupo e, em seguida, por temas utilizando a técnica de análise de conteúdo. A análise de conteúdo foi realizada de acordo com o preconizado por Bardin (2008), abrangendo uma primeira fase de leitura flutuante para familiarização com os dados de cada grupo. Em seguida, os trechos de respostas que se destacaram foram marcados com base na literatura- dimensões da experiência de Pine e Gilmore (1998) e Schmitt (2000). Ainda, outros trechos com temas que chamaram a atenção também foram destacados e categorizados, nomeando um tema a cada um deles. Esse procedimento foi feito por pares, visando contribuir para a validade do estudo. Os resultados encontrados foram comparados entre as impressões dos gestores e dos outros dois grupos.

Para facilitar a identificação dos responsáveis por cada fala, os gestores foram identificados com a letra $G$, entre 1 a 7 . $O$ grupo de moradores locais, pré visita, foi denominado de $A$, entre os números 1 a 30. Por fim, o grupo responsável pela visita ao CCBB$\mathrm{BH}$ foi chamado de grupo $\mathrm{B}$, com alunos identificados entre os números 1 a 18 .

Os trechos foram contrastados com a literatura relacionada ao marketing de experiência para atender ao objetivo geral de entender as impressões das pessoas a visitarem museus.

\section{Resultados}

Os resultados serão apresentados em três principais tópicos. 0 primeiro é referente à visão dos gestores e visitantes, buscando a abordagem comparativa proposta pelo estudo. O segundo tópico abrangeu as expectativas dos clientes quanto à visita aos museus, encontrando orientação ao aprendizado, orientação à cultura e orientação social como principais vertentes de análise. E o último diz respeito às dimensões da experiência de visita em museus, avaliando as dimensões da experiência memorável propostas pela literatura no contexto museológico.

\subsection{A visão dos gestores e dos visitantes}

Dentre os resultados desta pesquisa, foi possível notar avanços na visão do papel do museu pelos gestores, caminhando por meio de propostas que tentam mudar o entendimento do museu como um lugar de coisas antigas e obras intocáveis e pensar realmente os museus como espaço em constante transformação. Esse resultado vai de ao encontro com McLean (1995) e Rentscheller (2002), que demonstraram as transformações do entendimento dos espaços culturais na literatura.

Para alguns gestores, a experiência do visitante começa antes da visitação, e é realçada desde o primeiro contato pessoal na recepção de cada museu.

(G1) Temos cuidado com o acolhimento, que é feito na portaria, isso é algo que a gente tem renovado constantemente, mas sempre tem problema isso é inevitável, tem sempre alguém que não está satisfeito.

(G3) Primeiro que o visitante deve ser muito bem recebido, ele tem que ser muito bem acolhido desde a hora que ele entra no museu, a hora que ele chega no hall. Acho que esse é o primeiro impacto. Essa recepção no hall do museu tem ser muito bem feita.

(G4) Encantar na primeira visita, o nosso encantar começa desde a recepção que ele recebe na entrada da Casa Fiat, com treinamento da equipe que fica de receptivo.

(G6) A limpeza, a forma como ele é tratado na recepção (...) mas a primeira impressão do visitante é aquela porta da recepção.

Ainda, aspectos como interatividade, independência dos visitantes e a apresentação das obras de forma didática são destacados como pontos de atenção da experiência do museu.

\subsubsection{Interatividade}

Um dos aspectos que foi destacado por ambos os gestores e os visitantes foi a interatividade. Os visitantes esperam que a interatividade contribua para a experiência no museu, sendo tanto um elemento de expectativa (Grupo A) quanto de frustração quando não é gerido devidamente (Grupo B).

(A23) Um ambiente interativo pode ajudar, boas e informações sobre o que está exposto e também sobre os autores das obras. Uma boa contextualização da exposição.

(A27) Conhecimento nivelado, interatividade. [são fundamentais para uma experiência boa em um museu].

(B20) Os gestores precisam trabalhar mais a questão da interatividade. Provavelmente se tivesse um guia explicando a exposição, eu conseguiria absorver mais riqueza de detalhes das obras expostas.

(B14) Acho que os gestores do museu podem explorar mais o uso dos sentidos, de modo a interagir melhor o espetáculo cultural com os visitantes. 
Diretamente ligado ao tópico de interatividade, está também uma oportunidade de estratégia para os gestores, que, se considerarem a visão de alguns visitantes, deveriam investir em capacitação profissional e tecnologias inovadoras.

(B2) Os gestores deveriam focar em surpreender os visitantes, aliar a tecnologias às atividades interativas e espontâneas. Na minha opinião, isso atrai o público de todas as idades e torna a ida ao museu mais prazerosa.

(B9) Creio que os gestores do museu poderiam ter uma equipe mais treinada sobre o assunto que está exposto. Assim, eles poderiam explicar sobre as obras tornando a visita mais interativa.

\subsubsection{Independência dos visitantes durante a visita}

Alguns gestores reconhecem a existência de pessoas que não gostam de interferência durante sua experiência de visita, seja ela de funcionários ou de outros visitantes.

(G3) Há visitantes que não gostam de interferência nenhuma. Então que o visitante se sinta a vontade nessa casa para fazer ou a contemplação que ele quiser, ou buscar uma informação que ele julgue necessário, que ele tenha interesse.

(G6) No inicio, a gente fazia uma visita guiada, até quem concebeu achou que era a melhor maneira. A primeira coisa que a gente quis dar para o espaço foi essa independência do visitante, porque eu acho que isso também é muito importante atualmente, e a gente valoriza até no projeto educativo essa independência: eu posso chegar, posso ver fotografias, posso ir no café, posso ir na sala de leitura pegar um jornal, posso ver um show... então essa independência do visitante é uma coisa que a gente valoriza, fazer com que ele se sinta a vontade sem a interferência do segurança ou de um educador que vai perguntar "você precisa de alguma coisa?".

(G6) Dar independência; da impressão que ele tem do espaço, que vai desde a limpeza, segurança, manutenção predial.

Esta noção de não intervenção pessoal também foi destacada por alguns visitantes.

(A6) Guias que não irritem o visitante e grupos pequenos de visita.

(B15) Me incomodou apenas a presença de uma outra excursão de alunos de outra instituição que demonstravam claramente não ter um objetivo claro na visita e tumultuaram alguns dos ambientes disponíveis para visita.

Entretanto, parece ser necessário um equilíbrio entre espaço para independência do visitante e apoio para uma visita mais clara e encantadora.

(B4) Outro ponto a ser observado na visita, é o pouco preparo dos colaboradores do museu em relação ao público visitante, já que a grande maioria se mantém isolados e pouco receptivos a perguntas.

(B6) Não sei se o fato de não ser pago influencia, mas achei que faltaram guias para nos explicar sobre as obras e contextualizarnos, pois apesar de toda obra vir acompanhada de uma explicação, não eram suficientes para uma real compreensão.

(B18) Não tenho um conhecimento aprofundado sobre Kandinsky, então eu esperava algum tipo de auxílio, em alguns museus existem dispositivos de áudio sobre os temas em exposição ou pessoas oferecendo algum tipo de explicação.

Nesse sentido, as discussões sobre os níveis de interatividade, as políticas a serem adotadas e a capacitação dos funcionários devem prosseguir para encontrar uma melhor adequação entre o que o público quer e o que o museu pode prover.

\subsubsection{Didatismo}

Além da capacitação profissional, o principal ponto de melhoria presentado por aqueles que visitaram o museu (Grupo B) foi referente ao didatismo, isto é, deixar mais clara a relação entre as obras expostas e o objetivo da exposição como um todo.

(B6) Como não entendo muito sobre pinturas, não tive clara compreensão das mensagens nas obras (os textos informativos ajudaram para um maior entendimento).

(B2) Achei que a exposição em questões históricas ficou um pouco confusa, as artes não eram tão bem explicadas como por exemplo, havia uma roupa amostra mas não explicava quando e para qual ocasião o tipo de roupa era usada.

(B10) Melhorar a organização da exposição, fazendo com que as demais obras expostas não se misturem com as do autor principal - na minha opinião, isso facilitaria a vida dos visitantes.

(A16) A capacidade de dispor as informações de forma a não torná-las maçantes [é fundamental para uma experiência boa em um museu].

Percebe-se a necessidade de traduzir as obras e contextualizar o que se propõe com a exposição para gerar maior conexão entre visitante e espaço cultural.

Por outro lado, uma estratégia que tem sido apresentada pelos gestores de museus buscando a revisita e fidelidade dos clientes é a programação diversificada. Também há visitantes que ressaltam a importância desse tipo de atividade para atraí-los.

(G4) A gente mensalmente tem divulgação da programação nova. Na verdade, a gente tem a cada semana uma divulgação diferente. A gente tem vários sistemas. Então, por exemplo, mês que vem são quatro anos do Espaço, então a gente vai fazer uma programação especial.

(A14) Acho museus essenciais para a sociedade e para a cidade. Sinto-me especialmente motivado quando há exposições nãopermanentes e de assuntos que me interessam, como fotografia, grafite, moda e mesmo arte em telas.

Por fim, percebe-se uma transformação na visão dos museus. Por um lado, os gestores tentam se aproximar dos visitantes e montar exposições itinerantes e programação cultural variada. Por outro, os visitantes buscam por experiências novas e diferentes, por aprendizado e por cultura em espaços que oferecem convívio e informação, como será aprofundado no tópico seguinte.

\subsection{Expectativas sobre a visita a museus}

Sobre as expectativas de visitação, ou seja, o momento pré-visita, primeiramente é necessário apontar que tanto pessoas do Grupo $A$, quanto do Grupo $B$, destacaram não possuir interesse em visitar museus, corroborando o estudo de Gosling et al. (2014a). Algumas 
respostas sobre a relação dos respondentes com museus foram: "Não tenho costume de frequentar" (A17) e "Não possuo muito interesse ou motivação para visitar museus" (A18), "Confesso que nunca tive grandes interesses em visitar museus" (B1). Especificamente o gestor 4 aborda esta questão:

(G3) Muitas pessoas não gostam "não quero ver, não quero ir". Tem muita gente que não tem interesse por esse tipo de atividade, então é legítimo que o não-interesse exista.

(G4) A programação da Casa Fiat chama a atenção, tem pessoas que saem de outros estados para virem a exposições da Casa Fiat especificamente porque a gente faz um trabalho com acervos grandiosos de grandes coleções de grandes museus, inéditos e que a maioria das vezes não saem daqui, são pensados e idealizados por nós, apresentados pela primeira vez aqui e depois não se verá mais o que a gente apresenta. Isso sempre sustentou esse fluxo de público que tínhamos lá e estamos tendo aqui.

(G6) Então, hoje é impossível falar de programação de museu e de atuação de museu se você não traz a história da pessoa, a história daquele grupo, daquela sociedade pra dentro do espaço, você não causa reconhecimento.

De outra forma, aqueles que relataram visitar museus mostram ao menos três frentes de expectativas e interesses conforme apontado previamente por McLean (1997): 1) a fuga da rotina, 2) a sociabilidade e 3 ) a educação, que foram descritas tanto pelos gestores quanto por visitantes, mostrando um determinado alinhamento entre expectativas dos visitantes e dos gestores (ver Quadro 1).

\section{Quadro 1 - Expectativas e Interesses de visitantes de Museus.}

\begin{tabular}{|c|c|}
\hline Fuga da Rotina & $\begin{array}{l}\text { (A13) A experiência estética é algo transformador no sentido do deslocamento do indivíduo do lugar comum, do seu cotidiano. } \\
\text { Assim, quando o espectador entra em contato com algo que o faz refletir e, possivelmente, repensar suas atitudes e crenças, } \\
\text { ele passa por uma transformação. Museus são lugares muito favoráveis a essa experienciação. } \\
\text { (B14) Por fim, essa visita foi válida para experimentar e despertar sensações diferentes das que tenho em minha rotina, por } \\
\text { ser um programa totalmente fora dos meus costumes. }\end{array}$ \\
\hline Sociabilidade & $\begin{array}{l}\text { (A25) Na ultima vez que eu fui, foi no final do ano passado com uma irmã minha e um amigo, eles estavam visitando o BH ai } \\
\text { fomos no museu Vale na praça da liberdade, foi uma experiência bem legal, porque gostei muito do momento e além de ter } \\
\text { ido com eles. } \\
\text { (G2) Ao meu ver, a visita aos museus se dá principalmente pela influência social e pela curiosidade. A primeira trata de certa } \\
\text { "pressão social" que existe. Muitas vezes, pessoas que visitam museus e exposições são vistas como cultas e antenadas. (...) } \\
\text { Ou seja, a visita aos museus está relacionada a questão de status e de inclusão em um determinado circulo social. } \\
\text { (B17) A maioria das vezes que fui a um museu foi em acompanhamento a pessoas que haviam me convidado, o que configura } \\
\text { muito mais um evento social do que cultural. } \\
\text { (B7) Uma outra motivação de ir a museus é a minha família. Meu pai e minha mãe compartilham os mesmos sentimentos que } \\
\text { eu tenho quando vou nesses locais. E então considero esse tipo de passeio muito bom de fazer em família. }\end{array}$ \\
\hline Educação & $\begin{array}{l}\text { (A4) Como alguém que busca o novo, o esperado e a surpresa. Busco as diversas experiências que aquilo pode trazer, com } \\
\text { temas inovadores e críticos. Entre as motivações está a gratuidade da entrada, sempre é uma motivação, mas o conteúdo ainda } \\
\text { é a principal inspiração. } \\
\text { (G6) Eu acho que é o encantamento que ele causa, porque é uma museografia muito fácil, ela consegue emocionar, encantar } \\
\text { facilmente o público. (...) quando elas chegavam à galeria elas choravam quando viam a obra porque é realmente assim é um } \\
\text { trabalho muito dramático a pintura dele, então a gente percebe que tem um pouco da curiosidade, da vontade de agregar } \\
\text { conhecimento das pessoas de querer ver coisas novas. }\end{array}$ \\
\hline
\end{tabular}

Fonte: Autoria Própria.

Conforme apontado por Sheng e Chen (2011), outras duas expectativas também puderam ser identificadas neste estudo, a saber, a diversão, o entretenimento cultural e a rememoração histórica.

(B16) O que me motiva a visitar é a diversão e também por buscar por inspirações e referências criativas. (Diversão)

(A20) A última vez que visitei um museu foi com os meus pais e um tio, no final de semana. Estávamos em viagem e o museu é bem famoso, portanto era um dos pontos turísticos indispensáveis. (Entretenimento Cultural)

(A22) Quem vai a museus é uma pessoa que valoriza a história, está interessa em aprender mais sobre um assunto de interesse e também descobrir coisas novas. (Rememoração histórica)

Os achados acrescentam à teoria de expectativas de visitantes de museus ao apontar os seguintes tópicos:

1) Motivações diversas - uma pessoa pode possuir motivações diversas para visitar os museus, aliando, por exemplo, duas ou mais motivações.
2) Diferenças de Percepções - $O$ que pode ser visto como algo extremamente positivo para um visitante pode ser incômodo para outros, como é o caso da sociabilidade (vide comentários B17 e B7 no Quadro 1).

Além disso, há dois contextos importantes que direcionaram os resultados. O primeiro é a intenção de aprender ao visitar os museus. Gosling et al. (2014a) denominaram esta intenção de orientação ao aprendizado como a expectativa de se aprender ao visitar um museu. Outro contexto proposto por Gosling et al. (2014a) que também apareceu nesta pesquisa foi à orientação à cultura, isto é, o interesse por museus envolve um empenho cultural.

\subsubsection{Orientação ao Aprendizado}

Entrevistados expressaram a busca pelo aprendizado, justificando que um dos maiores motivos que levam as pessoas aos museus é conhecer mais sobre história, arte e aquisição de conhecimento.

Vários respondentes do Grupo A destacaram que quem vai a museus busca conhecimento, informação e aprender coisas novas. 
(A13) Acredito que os museus são os espaços de lazer que mais tentam conciliar o entretenimento ao aprendizado.

(A3) Minha relação com museus é boa e frequente (pelo menos três vezes ao ano) e motivada tanto por interesses de aprendizado quando de entretenimento.

(A14) (...) vou sempre que tem uma exposição interessante que ouvi falar ou então quando quero conhecer algo novo.

Tal motivação de busca pelo aprendizado apontada pelos entrevistados apresenta relação com o que McLean (1997) expõe quando afirma que os museus podem traduzir as informações exibidas em valores pessoais, cumprindo seu papel educacional. De acordo com Pine e Gilmore (1998), a dimensão educacional (absorção ativa) também faz parte do consumo da experiência, o que indica que a busca pelo aprendizado está diretamente ligada à busca por experiências novas e diferentes.

\subsubsection{Orientação à Cultura}

Os gestores apresentaram, em suas falas, que a imagem dos museus está ligada à possibilidade de vivenciar a cultura de modo geral.

(G2) Quanto à questão das experiências, o ponto forte do museu regional de Caeté é promover na cidade, que é tão carente de atividades culturais, eventos únicos que estimulem a convivência comunitária.

(G4) (...) percebemos que as pessoas já se apropriaram desse espaço, tem pessoas que entram olham, saem, vem tomar um café, vai à livraria, olha algo, percebemos que em quatro, cinco meses aqui já se consolidou em pouco tempo como um espaço aberto ao público e que as pessoas estão desfrutando.

(G5) Agora mudou a relação, eu quero saber o que é que tem nesse prédio, eu quero ver esse prédio, agora esse prédio - não que antes não fosse - mas agora ele pertence mais a sociedade, no sentido - não no pertencimento jurídico - mas do emocional, do social, do cultural.

Além disso, a pesquisa demonstrou que a visita a museus é parte de atividades culturais que os visitantes têm interesse, compondo sua rotina de lazer e de entretenimento.
(A8) Gosto de ir a shows, peças de teatro e exposições.

(A13) Gosto de ir a bares, a museus, a shows, assistir filmes e séries em casa, ler livros.

(A29) Gosto principalmente de ir em bares e boates. Às vezes vou a cinemas, e sempre fico de olho nas mostras que vêm à cidade.

Segundo Pine e Gilmore (1999), a experiência provê um mix de sensações físicas, emocionais, intelectuais e espirituais. Aplicandose ao universo dos museus o que Schmitt (1999) afirmou sobre os indivíduos estarem mais do que nunca em busca de experiências que deslumbrem seus sentidos, que os envolvam pessoalmente, e estimulem suas mentes.

\subsection{Dimensões da experiência de visita a museus}

A economia da experiência pode ser definida como o processo de vivenciar um acontecimento único e marcante. De acordo com Pine e Gilmore (1998), as empresas e instituições, apostam em proporcionar experiências memoráveis para seus consumidores. Um dos resultados da pesquisa, afirma que a experiência de visita em museu leva a lembranças de momentos de vida diversos, sejam eles de lazer, educativos ou viagens.

(B3) Essa visita me remeteu às excursões de colégio, onde era um dia totalmente diferente do que estávamos habituados.

(B6) Algumas pinturas e obras bem coloridas me lembraram duma viagem que fiz a Fortaleza, onde existiam artesões bem simplórios que faziam obras parecidas utilizando areias coloridas.

Porém, as lembranças suscitadas a partir da visita também podem ser negativas ou desagradáveis.

(B8) O fato de o museu ter várias partições e salas me vez lembrar da vez em que visitei um museu que era uma espécie de labirinto, nesta vez me perdi de minha tia e entrei em desespero até que com muita dificuldade voltei a encontrá-la.

As quatro dimensões da economia de experiência propostas por Pine e Gilmore $(1998,2011)$ foram identificadas no estudo no contexto de museus, bem como os dois eixos propostos pelos autores, como pode ser percebido no Quadro 2 .

\section{Quadro 2 - Dimensões e eixos da experiência de visita ao museu}

\begin{tabular}{l} 
Entretenimento \\
absorção passiva \\
\hline $\begin{array}{l}\text { Educacional } \\
\text { absorção ativa }\end{array}$ \\
Escapista \\
imersão ativa \\
Estética \\
(imersão passiva) \\
\hline $\begin{array}{l}\text { Eixo grau de } \\
\text { envolvimento } \\
\text { passivo versus ativo }\end{array}$ \\
Eixo conexão do \\
cliente com o \\
evento \\
absorção versus \\
imersão
\end{tabular}

(B2) Essa experiência me causou lembranças de bons momentos de lazer com meus amigos, nos divertimos, brincamos um com o outro, rimos e foi muito agradável.

(B20) eu conseguiria absorver mais riqueza de detalhes das obras expostas. Havia muitas explicações expostas, porém a limitação de tempo me restringiu de ler todas as informações divulgadas.

(B11) Uma das coisas que eu sempre sinto em visita à museus é que para ser uma experiência agradável você deve conseguir imergir no que aquele museus propõe, você precisa submergir totalmente a ponto de esquecer o que tem fora daquelas portas. Como se ao entrar no museu, vocês esquecesse sua própria realidade e vivesse aquela que está ali exposta. (B18) Discuti o significado de muitas obras com os colegas que visitaram a exposição comigo.

(B20) O que me chamou a atenção positivamente foi a estrutura luxuosa com que é decorado o ambiente, o requinte é um atrativo para os visitantes. Gostei das disposições e iluminações das obras de arte, muitas em posição de destaque dando enfoque ao seu valor.

(B14) Durante a visita eu não interagi muito com os outros alunos, vi a exposição mais sozinha. Os comentários que fiz com algumas pessoas em geral, foram mais sobre a beleza das obras da exposição.

(B18) Com a ajuda dos óculos 3D, foi possível obter uma interatividade maior com a obra.

(B19) O aproveitamento, por sua vez, poderia ter sido melhor se anteriormente tivesse sido apresentada a obra, explicando, mesmo que de forma superficial, os diversos estilos adotados pelo artista ao longo de sua carreira. Isto proporcionaria um melhor aproveitamento da visita, sobretudo na absorção do aspecto cultural.

(B11) Uma das coisas que eu sempre sinto em visita à museus é que para ser uma experiência agradável você deve conseguir imergir no que aquele museus propõe, você precisa submergir totalmente a ponto de esquecer o que tem fora daquelas portas.

Fonte: Autoria Própria. 
Além disso, também foi possível identificar os módulos estratégicos da experiência propostas por Schmitt (1999) no contexto de museus, conforme Quadro 3.

\begin{tabular}{l} 
Experiências sensoriais \\
Sentidos \\
$\begin{array}{l}\text { Experiências Afetivas } \\
\text { Sentimento }\end{array}$ \\
\hline $\begin{array}{l}\text { Experiências de Criatividade Cognitiva } \\
\text { Pensamento }\end{array}$ \\
\hline $\begin{array}{l}\text { Experiências físicas, comportamentos e } \\
\text { estilos de vida } \\
\text { Ação }\end{array}$ \\
\hline $\begin{array}{l}\text { Experiências de Identidade social } \\
\text { Relacionar-se }\end{array}$ \\
\hline
\end{tabular}

Contudo, por mais que a visita ao museu seja uma experiência que em alguns casos remeteram a emoções e a lembranças pessoais, a visita em si aparentou não ser memorável a ponto de ser marcante na vida dos alunos.

(B8) Foi interessante, apesar de não ter se tornado a mais memorável de todas.

(B14) Apesar de não me tocar ao ponto de ter sido uma experiência inesquecível, achei que foi uma experiência cultural que valeu muito a pena.

(B20) Gostei das obras que vi, mas não foi suficiente para criar uma experiência memorável.

Com isso, até que ponto a memorabilidade pode ser mensurada em estudos de experiência? Nesse sentido, novas pesquisas podem tentar verificar em que medida os museus podem de fato oferecer experiências memoráveis como proposto pela literatura de marketing de experiências.

\section{Considerações finais}

Este estudo reforça o desejo humano de experiências apontado por Hosany \& Witham (2009) e robustece a inserção dos espaços culturais na era da economia da experiência (Pine e Gilmore, 1998).

A pesquisa revelou que, de modo geral, as experiências buscadas pelos participantes na visitação de museus são ligadas ao entretenimento, à educação (obtenção de conhecimento) e ao aspecto estético. Tais aspectos corroboram com as dimensões da experiência abordadas por Pine e Gilmore (1998) - entretenimento, educacional, escapismo e estética, bem como por Schmitt (2000): sentidos, sentimento, pensamento, ação e relacionar-se.

Entretanto, há muito a ser feito pelos gestores para realçar a memorabilidade de visitas em museus, isto é, fazer dela uma experiência única e marcante no ponto de vista dos visitantes. Portanto, por mais que seja uma experiência que em alguns casos remeta a emoções e a lembranças pessoais, a visita em si pode não ser memorável a ponto de ser marcante na vida dos visitantes.

O estudo aponta para dois grandes eixos que servem como fonte de interesse para visitantes e devem ser explorados em estudos posteriores: a orientação à cultura e a orientação ao aprendizado.
Uma possível frente de pesquisa está na relação entre a organização das obras e o aprendizado, uma vez que o estudo apontou que a exposição das obras gerou reflexões distintas e pessoais, mas também confusão, atrapalhando o aprendizado de alguns visitantes. Alguns visitantes disseram não saber nada de arte, mas o museu não deveria ser um espaço de aprendizagem? A orientação à cultura também parece relacionada ao interesse e expectativa de se visitar museus, sendo algo extremamente relacionado a atividades de lazer e entretenimento.

Outro aspecto que merece mais investigação é como a companhia interfere na experiência. O estudo apontou que a companhia interfere nas três fases da visita. Na pré-visita, há uma pressão social para visitar um espaço cultural que estimula a visitação. Durante a visita, a troca de experiências e convívio, por vezes torna a visita mais agradável, através do compartilhamento de informações e interpretações. Por outro lado, alguns optam por realizar a visita sozinhos, relacionando o museu a um ambiente calmo e tranquilo. Com isso, a companhia também pode interferir negativamente para aqueles que preferem imergir no contexto das obras sem muita interferência de outros. Por fim, no momento pós-visita, a visita em grupos escolares, por exemplo, se mostrou como uma possibilidade de convidar outros a visitarem museus, inclusive familiares e amigos, instigando a revisita.

Finalmente, os principais pontos a serem considerados pelos gestores de museus para realçar a experiência dos visitantes são a divulgação do espaço, o treinamento dos funcionários, a interatividade- seja por meio de aparatos tecnológicos ou relacionamento interpessoal. Outra linha que tem sido adotada pelos gestores e parece ser um bom caminho para fidelização dos visitantes é a rotatividade de exposições e a oferta de programação cultural variada, com eventos de interesse dos visitantes.

Esta pesquisa não está isenta de limitações, uma vez que não se observou a experiência em si e a análise da visita foi feita via entrevista, após a visita e se limitando a um museu apenas com exposição itinerante, o que restringe sua aplicação em outras exposições e espaços culturais. Além disso, o público selecionado para o estudo não permite generalizações, apesar de abrir espaço para outras pesquisas correlatas. 


\section{Agradecimentos}

Agradecemos à Fapemig e à Capes pela contribuição para o desenvolvimento do projeto.

\section{Referências}

Bardin, L. (2008). Análise de conteúdo, 4. ed. Lisboa: Edições 70.

Del Chiappa, G., Andreu, L. \& Gallarza, M. G. (2014): Emotions and visitors' satisfaction at a museum. International Journal of Culture, Tourism and Hospitality Research, 8 (4), 420-431.

Doering, Z. (1999). Strangers, Guests, or Clients? Visitor Experiences in Museums. Curator: The Museum Journal. 42 (2), 74-87.

Falk, J. H. \& Dierking, L. D. (1992): The Museum Experience. Washington: D.C.Whalesback Books.

Gosling, M., Coelho, M. \& Resende, M. P. (2014a). Qualidade percebida e intenções comportamentais de visitantes em museus : uma proposta de modelo. Revista Turismo Visão e Ação, 16 (3), 656-689.

Gosling, M., Pereira, G. D. A., Vera, L. A. R., Coelho, M. D. F. \& Lima, C. G. (2014b). Vamos fazer algo diferente? Um estudo exploratório sobre motivações de visitação a museus. Vianna Sapiens, 5 (2), 336-360.

Goulding, C. (2000). The Museum Environment and the Visitor Experience. European Journal of Marketing, 34 (3/4). 261-278.

Grenier, R. (2010). All work and no play makes for a dull museum visitor. New directions for adult and continuing education, 127, 77-85.

Hiller, M. (2011): Uma experiência Estética e de Marketing em Museus. Disponível em: <http:// faculdadefundetec.com.br/img/revista_academica/pdf/artigo_hiller.pdf>. Acesso em: 30 de junho de 2014.

Hosany, S. \& Witham, M. (2009). Dimensions of cruisers' experiences, satisfaction, and intention to recommend. Journal of Travel Research, 49 (3), 351-364.

Kim, J., Ritchie, B. \& McCormick, B. (2012). Development of a Scale to Measure Memorable Tourism Experiences. Journal of Travel Research, 51 (1), 12-25

Kim, J. \& Ritchie, J. R. B. (2014). Cross-cultural validation of a memorable tourism experience scale (MTES). Journal of Travel Research, 53 (3), 323335.

Kirchberg, V. \& Tröndle, M. (2012).Experiencing Exhibitions: A Review of Studies on Visitor Experiences in Museums. Curator: The Museum Journal, 55 (4), 435-452.

Larsen, S. (2007). Aspects of a psychology of the tourist experience. Scandinavian Journal of Hospitality and Tourism, 7 (1), 7-18.

Lusch, R. F. \& Vargo, S. L. (2014). Service-Dominant Logic: Premises, Perspectives, Possibilities. Cambridge, UK : Cambridge University Press.

McLean, F. (1995). A Marketing Revolution in Museums? Journal of Marketing Management, 11, 601-616.

McLean, F. (1997). Marketing the Museum. New York: Routledge.

Munar, A. M. \& Jacobsen, J. K. S. (2014). Motivations for sharing tourism experiences through social media. Tourism Management, (43), 46-54.

Pezzi, E. (2015). A experiência turística e o turismo de experiência: um estudo sobre as dimensões da experiência memorável. Turismo em Análise, 26 (1), 165-187.

Pine, J. \& Gilmore, G. H. (1998). Welcome to the experience economy. Harvard Business Review, 76 (4), 97-105.

Pine, B. J. P. \& Gilmore, J. H. (2011). The Experience Economy. Boston: Harvard Business Review Press.

Prahalad, C. \& Ramaswamy, V. (2004). The future of competition: cocreating unique value with customers. Boston: Harvard Business School Press.

Rentscheller, R. (2002). Museum and Performing Arts Marketing: The Age of Discovery. The Journal of Arts Management, Law, and Society, 32 (1), 7-14.

Schmitt, B. H. (1999). Experiential Marketing: How to Get Customers to Sense, Feel, Think, Act, Relate to Your Company and Brands. New York: The Free Press.

Schmitt, B. (2000): Marketing experimental. São Paulo: Nobel.
Shaw, C. \& Ivens, J. (2002). Building Great Customer Experiences. New York Palgrave Macmillan.

Sheng, C-W. \& Chen, M-C. (2012). A study of experience expectations of museum visitors. Tourism Management, 33 (1), pp. 53-60.

Silva, P. \& Santos, G. (2011). A qualidade da experiência dos visitantes ao Museu do Futebol. Observatório de Inovação do Turismo - Revisto Acadêmica, 6 (2), 1-19.

Soares, C. T. S. (2010). O processo de significação da experiência museal: um estudo sobre o contexto pessoal dos professores de Ciências. Dissertação: Mestrado em Educação - PUC, Porto Alegre.

Thyne, M. (2000). The Importance of values research for nonprofit organisations: The motivation-based values of museum visitors.International Journal of Nonprofit and Voluntary Sector Marketing, $6(2), 116-130$.

Thyne, M.; Hede, A. M. \&White, T. (2009). Co-constructing the museum visitors' experience: a case of two literary museums. Proceedings of 'Sustainable Management and Marketing', 23rd Annual Australian and New Zealand Marketing Academy Conference (ANZMAC), Melbourne, Victoria, Australia.

Weil, W. E. (2000). Transformed form a cemetery of bric-a-brac. In Sheppard, B. (Ed.), Perspectives on outcome based evaluation for libraries and museums. Washington, D.C.: Institute of Museum and Library Services.

Recebido: 06.01.2016

Reenviado: 01.06.2016

Aceite: 02.06.2016

\section{Apêndice}

\section{Roteiro Gestores - Grupo G: 7 gestores}

1. Na sua opinião, qual a função de um museu?

\section{Motivações dos visitantes}

2. Porque as pessoas visitam este museu especificamente, quais seriam os motivos de elas virem aqui?

3. E o que os visitantes procuram ou buscam encontrar quando eles vêm aqui?

4. Existe uma motivação material específica que é procurada? algum tipo de experiência?

5. Que tipo de conhecimento os visitantes buscam aqui no museu? É um conhecimento específico?

Perfil

6. O que você teria a dizer sobre o (s) perfil(s) de público que visitam o museu?

(Existe alguma época em que o espaço é mais frequentado? Existe alguma loja de lembrancinhas? Existe alguma forma dos visitantes fazerem sugestões?)

7. As pessoas que geralmente vêm aqui o fazem de forma autônoma ou tem algum programa de incentivo para trazê-los?

8. Gostaríamos de saber um pouco sobre as pessoas que não vêm Existe algum fator interno ou externo do museu que dificulta a visita no mesmo?

\section{Ações do museu para o visitante}

9. A equipe do museu se preocupa com a experiência proporcionada pelo museu ao visitante? De que forma?

10. Existe uma programação do museu? Qual a periodicidade de troca de programação? É feita alguma divulgação da programação?

11. Existe algum tipo de ação com o sentido de propor que a pessoa visite o museu mais de uma vez ou retorne aqui?

Satisfação/ Recomendação

12. Sobre a satisfação dos visitantes, existe algo que é feito para que os visitantes saiam daqui satisfeitos? Ou, ainda, existe algo que pode ser feito para que eles saiam daqui ainda mais satisfeitos? 
13. As pessoas costumam recomendar o museu? Por que você acredita que isso ocorre?

14. Há algum comentário que você gostaria de fazer a respeito de problemas ou propostas de melhorias da experiência do visitante?

Roteiro Pré visita - Grupo A: 30 visitantes

1. O que você gosta de fazer em termos de lazer, entretenimento?

2. Você investe (ou gasta) seu tempo de lazer a entretenimentos ligados à cultura? Em que circunstâncias e com qual frequência?

3. Você investe (ou gasta) seu tempo de lazer a entretenimentos ligados ao aprendizado, ao conhecimento? Em que circunstâncias e com qual frequência?

4. Qual a sua relação com museus? (interesse, motivações para visita, frequência de visitas, etc)

5. Quem vai a museus é..

6. Quem frequenta museus busca...

7. A visita a um Museu pode transformar um indivíduo? Como?

8. E sobre o nível de conhecimento prévio do indivíduo? Qual a mudança (se você achar que possa haver) uma visita a um Museu acrescenta o conhecimento prévio do indivíduo? Por quê?

9. Detalhe as circunstâncias da sua última visita a um museu.

10. Quais aspectos você acha fundamentais que para que o visitante tenha uma experiência realmente boa no Museu, saindo de lá satisfeito?

Roteiro Pós Visita - Grupo B: 18 visitantes

1. Qual a sua relação com museus? (interesse, motivações para visita, frequência de visitas, etc).

2. Você já tinha visitado o CCBB-BH? Se sim, explique a situação.

3. Em geral, o que você achou da visita?

4. A experiência te evocou algum tipo de lembrança ou emoção? Descreva-as.

5. Que elementos te surpreenderam positivamente?

6. Que elementos te surpreenderam negativamente?

7. Você aprendeu alguma coisa com a visita? Explique.

8. Você recomendaria o museu para outras pessoas?

9. Você acha que a companhia afetou sua experiência? Como?

10. O que você acha que os gestores do museu podem fazer para melhorar as experiências dos visitantes?

Há algo mais que gostaria de completar/destacar da sua visita? 